\title{
Analysis of Anthrax Immune Globulin Intravenous with Antimicrobial Treatment in Injection Drug Users, Scotland, 2009-2010
}

\author{
Xizhong Cui, ${ }^{1}$ Leisha D. Nolen, ${ }^{1}$ Junfeng Sun, Malcolm Booth, Lindsay Donaldson, \\ Conrad P. Quinn, Anne E. Boyer, Katherine Hendricks, Sean Shadomy, Pieter Bothma, \\ Owen Judd, Paul McConnell, William A. Bower, Peter Q. Eichacker
}

\begin{abstract}
Medscape ACTIVITY
This activity has been planned and implemented through the joint providership of Medscape, LLC and Emerging Infectious Diseases. Medscape, LLC is accredited by the American Nurses Credentialing Center (ANCC), the Accreditation Council for Pharmacy Education (ACPE), and the Accreditation Council for Continuing Medical Education (ACCME), to provide continuing education for the healthcare team.

Medscape, LLC designates this Journal-based CME activity for a maximum of 1.00 AMA PRA Category 1 Credit(s) ${ }^{\mathrm{TM}}$. Physicians should claim only the credit commensurate with the extent of their participation in the activity.

All other clinicians completing this activity will be issued a certificate of participation. To participate in this journal CME activity: (1) review the learning objectives and author disclosures; (2) study the education content; (3) take the post-test with a $75 \%$ minimum passing score and complete the evaluation at

http://www.medscape.org/journal/eid; and (4) view/print certificate. For CME questions, see page 175.
\end{abstract}

Release date: December 15, 2016; Expiration date: December 15, 2017

Learning Objectives

Upon completion of this activity, participants will be able to:

1. Assess recommendations for the management of systemic anthrax and the use of anthrax immune globulin intravenous (AIG-IV)

2. Distinguish variables associated with the application of AIG-IV in the current study

3. Assess outcomes of patients treated with AIG-IV in the current study

4. Evaluate the efficacy of AIG-IV in the current study

CME Editor

Karen L. Foster, Technical Writer/Editor, Emerging Infectious Diseases. Disclosure: Karen L. Foster has disclosed no relevant financial relationships.

CME Author

Charles P. Vega, MD, Clinical Professor of Family Medicine, University of California, Irvine. Disclosure: Charles $P$. Vega, MD, has disclosed the following financial relationships: served as an advisor or consultant for Allergan, Inc.; McNeil Consumer Healthcare; served as a speaker or a member of a speakers bureau for Shire Pharmaceuticals.

\section{Authors}

Disclosures: Xizhong Cui, MD, PhD; Leisha D. Nolen, MD, PhD; Junfeng Sun, PhD; Malcolm Booth, MB ChB, FRCA, MPhil, FFICM; Lindsay Donaldson, MB ChB, FRCA, FFICM, FRCP; Conrad P. Quinn, PhD; Anne E. Boyer, PhD; Katherine Hendricks, MD, MPH\&TM; Sean Shadomy, DVM, MPH, Diplomate ACVPM; Pieter Bothma, MB ChB M. Med, FCA(SA); Owen Judd, BM BS, FRCS, FRSA; Paul McConnell, MB ChB, FRCA, EDIC, FFICM; William A. Bower, MD; and Peter Q. Eichacker, MD, have disclosed no relevant financial relationships.

Author affiliations: National Institutes of Health, Bethesda, Maryland, USA (X. Cui, J. Sun, P.Q. Eichacker); Centers for Disease Control and Prevention, Atlanta, Georgia, USA (L.D. Nolen, C.P. Quinn, A.E. Boyer, K. Hendricks, S. Shadomy, W.A. Bower); Glasgow Royal Infirmary, Glasgow, UK (M. Booth, L. Donaldson); James Paget University Hospital, Norfolk, UK
(P. Bothma); Royal Derby Hospital, Derby, UK (O. Judd); Crosshouse Hospital, Kilmarnock, UK (P. McConnell)

DOI: http://dx.doi.org/10.3201/eid2301.160608

${ }^{1}$ These authors contributed equally to this article. 
We studied anthrax immune globulin intravenous (AIG-IV) use from a 2009-2010 outbreak of Bacillus anthracis soft tissue infection in injection drug users in Scotland, UK, and we compared findings from 15 AIG-IV recipients with findings from 28 nonrecipients. Death rates did not differ significantly between recipients and nonrecipients ( $33 \%$ vs. $21 \%$ ). However, whereas only $8(27 \%)$ of 30 patients at low risk for death (admission sequential organ failure assessment score of $0-5)$ received AIG-IV, 7 (54\%) of the 13 patients at high risk for death (sequential organ failure assessment score of 6-11) received treatment. AIG-IV recipients had surgery more often and, among survivors, had longer hospital stays than did nonrecipients. AIG-IV recipients were sicker than nonrecipients. This difference and the small number of higher risk patients confound assessment of AIG-IV effectiveness in this outbreak.

$B$ acillus anthracis is identified as a select agent subject to select agent regulations (1-3) and as a potential bioweapon that presents a high risk to the US public $(4,5)$. Production of lethal toxins and edema toxins by $B$. anthracis is central to the bacterium's pathogenesis $(6-8)$. The Centers for Disease Control and Prevention (CDC) guidelines now recommend that patients with clinical evidence of systemic anthrax disease receive an antitoxin agent in combination with antimicrobial agents (9).

Anthrax immune globulin intravenous (AIG-IV; current trade name Anthrasil, manufactured by Emergent BioSolutions Inc., Rockville, MD, USA) is one of the few antitoxin agents approved by the Food and Drug Administration (FDA) and included in the Strategic National Stockpile (10). It is a polyclonal human antibody prepared from the serum of persons previously vaccinated with anthrax vaccine adsorbed (BioThrax; Emergent BioSolutions, Gaithersburg, MD, USA). Because of the infrequency of invasive $B$. anthracis infection, AIG-IV approval was based on its efficacy in anthrax animal models in combination with safety data from healthy humans $(11,12)$. Therefore, although AIG-IV has been the only antitoxin therapy administered clinically since the 2001 US anthrax outbreak, its actual efficacy in humans is unknown. Reviewing clinical experiences where AIG-IV has been administered for anthrax is important to inform future use of this agent and of antitoxin agents in general.

Although AIG-IV use has been reported in 3 isolated anthrax cases (13-16), the largest clinical experience with it came during an outbreak of $B$. anthracis soft tissue infection in injection drug users in the United Kingdom during 2009-2010. These cases were secondary to heroin injections contaminated with the same $B$. anthracis strain (17-24). Of the 52 confirmed cases in this outbreak, 47 occurred in Scotland, and 15 of these persons received AIGIV through the coordinated efforts of CDC, Health Protection Scotland (HPS), and the Scottish National Anthrax
Outbreak Control Team. Although the epidemiology of this outbreak and the clinical characteristics of a subgroup of 27 patients has been reported, a review of experience with AIG-IV itself and its effects on recovery has not $(18,25)$. Here we examine that experience in 15 recipients and 28 nonrecipients of the agent.

\section{Methods}

\section{Approval}

This study used de-identified data collected during routine hospital care of patients. The Office of Human Subjects Research from the Clinical Center at the National Institutes of Health (Bethesda, MD, USA) determined the study to be exempt from institutional review board review.

\section{AIG-IV Availability, Distribution, and Administration}

Representatives of CDC and the Scottish National Anthrax Outbreak Control Team directly involved with the 20092010 UK anthrax outbreak provided information about how AIG-IV was distributed and administered. Data from a previously published survey of physicians caring for patients during the outbreak were also reviewed (18).

\section{Clinical Characteristics and Outcomes Comparing AIG-IV Recipients and Nonrecipients}

Data regarding the clinical characteristics and outcomes of patients came from 2 sources. One was clinical data CDC obtained under its AIG-IV emergency investigational new drug application (E-IND). The other was from a previous survey of physicians caring for patients during the outbreak that had sought information about the disease characteristics, care, and outcome of patients (18). This previous survey did not compare AIG-IV recipients and nonrecipients.

\section{Lethal Factor Level Determinations}

Lethal factor (LF) toxemia was quantified at CDC's Clinical Chemistry Branch, Division of Laboratory Sciences (Atlanta, GA, USA), by using a validated mass spectrometry method that reports specific LF endoproteinase activity in nanograms per milliliter of serum. The LF mass spectrometry assay had precision of $8 \%-14 \%$, accuracy of $92 \%-98 \%$, and $100 \%$ diagnostic sensitivity and specificity (26).

\section{Data Analysis}

We analyzed parameters for which $>50 \%$ of patients had data reported for that parameter. The sequential organ failure assessment (SOFA) scores analyzed were those recorded by physicians caring for patients (27). Categorical data were analyzed with $\chi^{2}$ if not sparse or with Fisher exact test if otherwise. Normally distributed continuous data were analyzed by calculating the mean $\pm \mathrm{SE}$ and 
compared between groups by using 2-sample $t$ tests. Otherwise, data were summarized with medians (interquartile range [IQR]). Times from exposure to symptom onset; from symptom onset to hospital admission; and from hospital admission to anthrax diagnosis, surgery, AIG-IV administration, and intensive care unit (ICU) or hospital discharge were compared with Wilcoxon rank sum tests, and physical and laboratory findings not normally distributed were log-transformed and then compared by using 2-sample $t$ tests. To assess the trend of LF over time, we used a linear regression model with a common slope and different intercepts for survivors and nonsurvivors. LF levels were $\log _{10}$-transformed, and a random subject effect was used to account for repeated measures. We considered 2-sided $\mathrm{p}$ values $\leq 0.05$ to be significant without adjusting for multiple comparisons. All analysis were done by using SAS version 9.3 (SAS Institute, Cary, NC, USA).

\section{Results}

\section{Outbreak}

During the $B$. anthracis outbreak in the United Kingdom during December 9, 2009-July 12, 2010, a total of 47 confirmed cases were reported in Scotland from 14 hospitals. A case was defined as confirmed on the basis of a positive bacterial culture or PCR result from blood or tissue or on paired serology samples showing increasing antibody protective antigen or LF titers (25).

\section{AIG-IV Availability, Distribution, and Administration}

During the outbreak, 15 patients received AIG-IV under the CDCs E-IND, and all treatments were from the same AIG-IV batch (Cangene Corp., Winnipeg, MB, Canada). CDC's Division of Strategic National Stockpile provided the first set of AIG-IV doses for use on December 18, 2009, and a limited number of AIG-IV doses were available throughout the remainder of the outbreak. HPS distributed AIG-IV during the outbreak. Clinicians identified patients for AIG-IV treatment in accordance with criteria outlined in the E-IND and published by HPS (28). To be eligible to receive AIG-IV, patients had to have laboratory confirmation of $B$. anthracis infection based on positive cultures or PCR results; visualization of grampositive bacilli from blood, tissue, or a normally sterile site; or other confirmed evidence of anthrax (e.g., positive paired serologic results as noted earlier) consistent with $B$. anthracis infection (Table 1). Having met these criteria, however, whether a patient was administered AIG-IV was at the discretion of the treating physicians and their impression that a patient would or would not benefit from this treatment.

Under the E-IND, patients receiving AIG-IV were assessed, and baseline status was recorded before AIG-IV administration. All patients received a single similar dose (420 U) of AIG-IV. Patients were then monitored during and after the infusion until discharge. Monitoring during infusion frequently occurred in the ICU.

\section{Initial Clinical Characteristics of AIG-IV Recipients and Nonrecipients}

For 43 patients, data were available for review and analysis, including for all 15 AIG-IV recipients. Times from contaminated heroin exposure to symptom onset and from symptom onset to hospitalization did not differ significantly between AIG-IV recipients and nonrecipients (Figure 1; Table 2). Age, sex, smoking status, excessive alcohol use, hepatitis $\mathrm{C}$ status, and use of different routes or limbs for drug injection did not differ significantly (Table 2). The proportion of patients who had only localized skin or limb complaints or only generalized complaints or a combination of localized and generalized complaints did not differ significantly between AIG-IV recipients and nonrecipients (Table 2). Among AIG-IV recipients, neither the time from exposure to AIG-IV treatment between survivors and nonsurvivors (median [IQR] 8 [6.5-11.0] days vs. 5.5 [3.07.0] days; $p=0.12]$ nor the time from symptom onset to treatment (4 [1-8] days vs. 4 [3-5] days; $\mathrm{p}=0.59$ ] differed significantly.

On initial physical examination, AIG-IV recipients had lower body temperature than nonrecipients (mean \pm SE $36.3^{\circ} \mathrm{C} \pm 0.4$ vs. $37.3^{\circ} \mathrm{C} \pm 0.3 ; \mathrm{p}=0.05$ ), but heart and respiratory rates and blood pressure, and Glasgow coma scores (GCS) did not differ significantly (Table 3). Although a smaller proportion of recipients had limb edema

\footnotetext{
Table 1. Clinical criteria for administering anthrax immune globulin intravenous during an outbreak of anthrax in injection drug users, Scotland, UK, 2009-2010

Criteria

1. Systemic illness in a heroin user with $\geq 1$ of the following:

a. Severe cellulitis, especially accompanied by substantial soft tissue edema

b. Sudden onset of sepsis with no other obvious source

c. Meningitis, which might also be characterized by subarachnoid hemorrhage

d. Respiratory symptoms (suspect inhalational anthrax)

e. Gastrointestinal symptoms (suspect gastrointestinal anthrax);

OR

2. Features clinically compatible with cutaneous, inhalation, or gastrointestinal illness with systemic effects (including malaise, myalgias, or fever).

In addition to 1 or 2 :

Laboratory confirmation by isolation or visualization of a gram-positive bacillus consistent with Bacillus anthracis from blood, tissue, or a normally sterile site or other laboratoryconfirmed evidence of anthrax infection after discussion with a local microbiologist or the Special Pathogens Reference Laboratory, Health Protection Agency, Porton Down, UK; AND

An epidemiologic link to a documented anthrax exposure (such as being a heroin injecting drug user).
} 
(7 [47\%] of 15 vs. 21 [84\%] of $25 ; p=0.03]$ and limb pain (7 [47\%] of 15 vs. 17 [89\%] of $19 ; p=0.01$ ), neither the presence nor type of skin finding differed significantly between the groups (Table 3). Although a greater proportion of nonrecipients had confusion (6 [35\%] of 17 vs. 0 of 13 ; $\mathrm{p}=0.02)$, other nonskin and nonlimb findings did not differ significantly between groups.

We compared results of initial laboratory results of AIG-IV recipients and nonrecipients. Recipients had higher total levels than nonrecipients for leukocytes (median [IQR] 18.9 [9.5-23.2] vs. 10.9 [8.6-14.1] cells $\times 10^{3}$ cells $\left./ \mu \mathrm{L} ; \mathrm{p}=0.02\right)$; neutrophils $(15.4$ [7.4-19.5] vs. 7.6 $[5.2-10.0] \times 10^{3}$ cells $\left./ \mu \mathrm{L} ; \mathrm{p}=0.008\right)$; blood urea nitrogen $(8.6[7.1-13.9]$ vs. $4.3[3.7-6.0] \mathrm{mmol} / \mathrm{L} ; \mathrm{p}=$ $0.01)$; creatinine $(102.0$ [84.0-189.0] vs. 75.5 [64.0$89.5] \mathrm{mmol} / \mathrm{L} ; \mathrm{p}=0.04)$; and bilirubin (13.5 [9.0-17.0] vs. $8.0[5.0-11.0] \mu \mathrm{mol} / \mathrm{L} ; \mathrm{p}=0.02)$ but lower levels for bicarbonate (mean \pm SE $20.7 \pm 0.9$ vs. $24.4 \pm 1.2$ $\mathrm{mmol} / \mathrm{L} ; \mathrm{p}=0.02)$; alkaline phosphatase (85 [56-97] vs. 100 [74-189] U/L; $\mathrm{p}=0.04)$; total protein (46 [41-62]
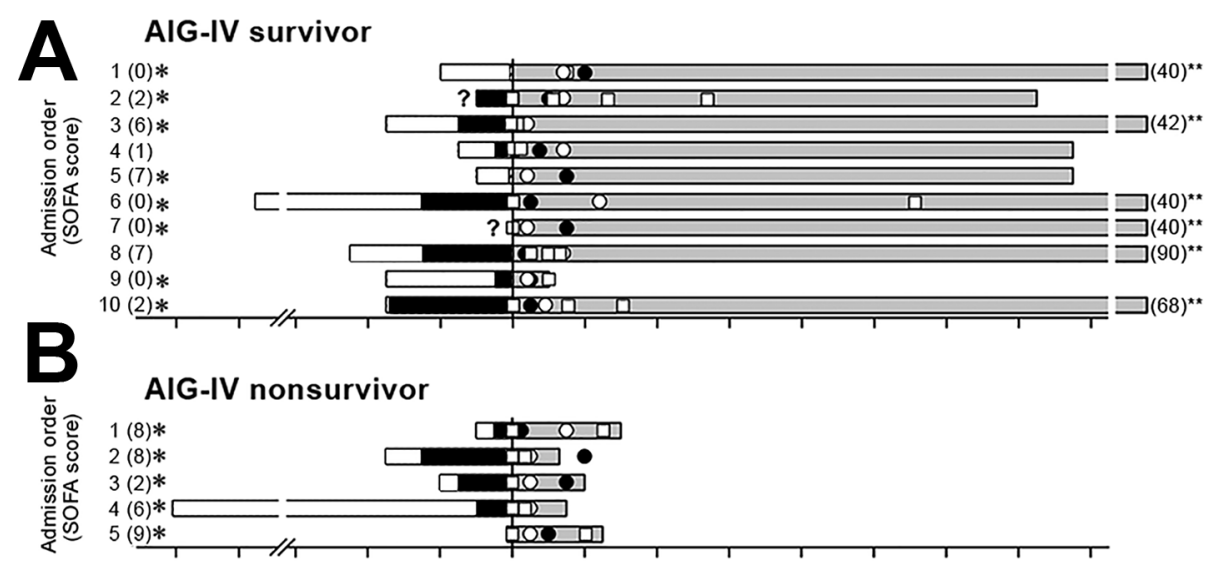

C

Non-AIG-IV survivor

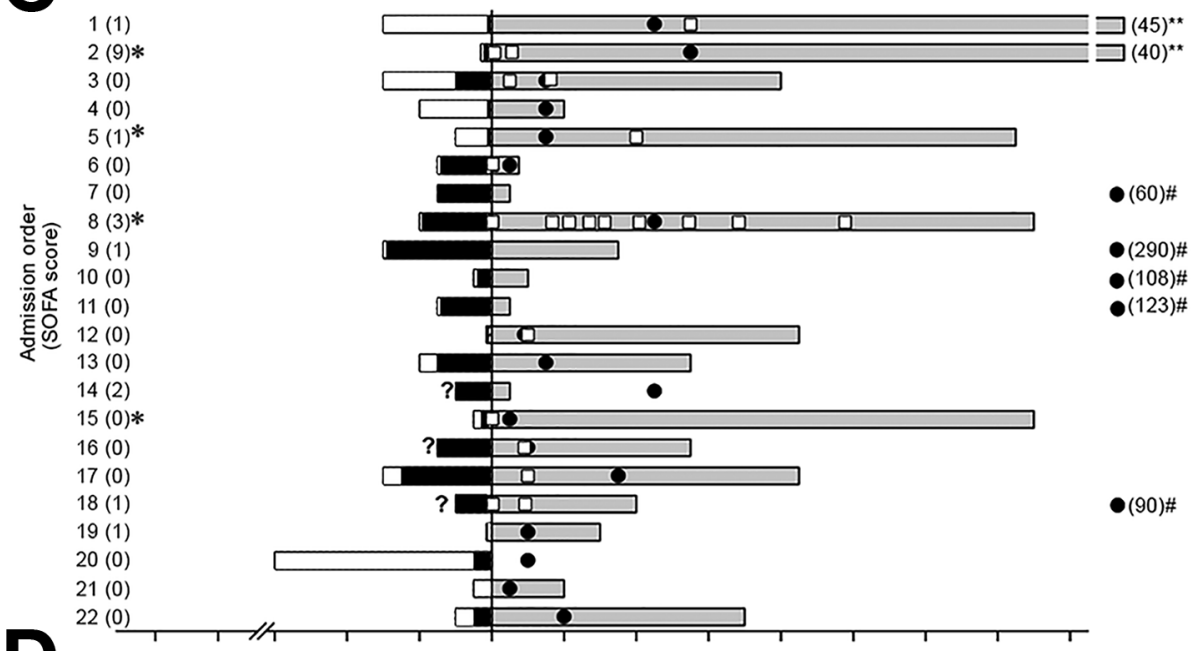

Non-AIG-IV nonsurvivor

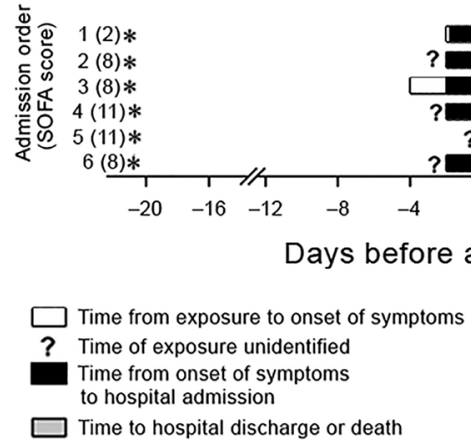

Emerging Infectious Diseases • www.cdc.gov/eid • Vol. 23, No. 1, January 2017
Figure 1. Key events during the illness courses of 15 patients who received AIG-IV (10 survivors, 5 nonsurvivors) and 28 patients who did not receive AIG-IV (22 survivors, 6 nonsurvivors) from the time of their suspected exposure to contaminated heroin to the time of discharge from hospital or to death, Scotland, UK, 2009-2010. A) AIG-IV recipient who survived. B) AIG-IV recipient who died. C) AIG-IV nonrecipient who survived. D) AIG-IV nonrecipient who died. AIG-IV, anthrax immune globulin intravenous; ICU, intensive care unit; SOFA, sequential organ failure. 
Table 2. Medical history of AIG-IV recipients and nonrecipients, Scotland, UK, 2009-2010*

\begin{tabular}{|c|c|c|c|}
\hline Variable & AIG-IV nonrecipient & AIG-IV recipient & $\mathrm{p}$ value \\
\hline \multicolumn{4}{|l|}{ Presentation and clinical history } \\
\hline Days from exposure to symptom onset, median (IQR) & $1(0.0-4.0), n=18$ & $2(1.0-4.5), n=12$ & 0.19 \\
\hline Days from symptom onset to hospitalization, median (IQR) & $2(1.0-3.0), n=25$ & $2.0(1.0-5.0), n=14$ & 0.55 \\
\hline Age, y, mean \pm SE & $34.2 \pm 1.5, \mathrm{n}=28$ & $37.5 \pm 1.6, n=15$ & 0.18 \\
\hline Male sex & $60.7(17 / 28)$ & $73.3(11 / 15)$ & 0.41 \\
\hline Smoker & $94.4(17 / 18)$ & $81.8(9 / 11)$ & 0.54 \\
\hline Alcohol user & $33.3(5 / 15)$ & $58.3(7 / 12)$ & 0.19 \\
\hline Hepatitis C infection & $60(9 / 15)$ & $77.8(7 / 9)$ & 0.66 \\
\hline \multicolumn{4}{|l|}{ Drug injection route and site } \\
\hline Intravenous & $50(14 / 18)$ & $40(6 / 15)$ & 0.53 \\
\hline Intramuscular & $21.4(6 / 28)$ & $46.7(7 / 15)$ & 0.16 \\
\hline Arm & $39.3(11 / 28)$ & $26.7(4 / 15)$ & 0.41 \\
\hline Groin & $25(7 / 28)$ & $26.7(4 / 15)$ & 1.00 \\
\hline Buttock & $7.1(2 / 28)$ & $26.7(4 / 15)$ & 0.16 \\
\hline Leg & $10.7(3 / 28)$ & $6.7(1 / 15)$ & 1.00 \\
\hline \multicolumn{4}{|l|}{ Presenting complaints } \\
\hline Local† & $67.9(19 / 28)$ & $53.3(8 / 15)$ & 0.54 \\
\hline General & $17.9(5 / 28)$ & $20.0(3 / 15)$ & \\
\hline Both\% & $14.3(4 / 28)$ & $26.7(4 / 15)$ & \\
\hline
\end{tabular}

*Values are \% patients (no. patients with the finding/no. patients for whom data were available) except as indicated. $\mathrm{n}$ values indicate number of patients for whom data were available. AIG-IV, anthrax immune globulin intravenous; IQR, interquartile range.

†Skin lesion, limb swelling, or limb pain.

$\ddagger$ Fever, diaphoresis, confusion, seizures, lethargy, or malaise.

vs. $67[65-75] \mathrm{g} / \mathrm{L} ; \mathrm{p}=0.001) ;$ and albumin $27.6 \pm 2.6$ vs. $38.3 \pm 1.1 \mathrm{~g} / \mathrm{L} ; \mathrm{p}<0.0001$ ) levels (Table 4$)$. Other laboratory parameters did not differ significantly between the 2 groups (Table 4).

On microbiological examination, a higher proportion of AIG-IV recipients than nonrecipients had positive blood cultures $(10[71 \%]$ of 14 vs. 8 [32\%] of $25 ; p=$
$0.02)$ and positive blood PCR results (8 [80\%] of 10 vs. 5 $[29 \%]$ of $17 ; \mathrm{p}=0.02$ ) for $B$. anthracis (Table 5 ). Other microbiological data did not differ significantly between the 2 groups (Table 5). The time to anthrax diagnosis was shorter for AIG-IV recipients than for nonrecipients (median [IQR] $2.0[1.0-3.0]$ vs. $3.5[2.0-30.5] ; \mathrm{p}=0.006]$ (Figure 1; Table 5).

\begin{tabular}{|c|c|c|c|}
\hline Physical finding & AIG-IV nonrecipient & AIG-IV recipient & $p$ value \\
\hline \multicolumn{4}{|l|}{ Vital signs [reference value]† } \\
\hline Temperature, ${ }^{\circ} \mathrm{C}$, mean $\pm \mathrm{SE}\left[36.1-37.2^{\circ} \mathrm{C}\right]$ & $37.3 \pm 0.3, n=28$ & $36.3 \pm 0.4, n=15$ & 0.05 \\
\hline Systolic BP, mmHg, mean \pm SE $[90-140 \mathrm{~mm} \mathrm{Hg}]$ & $113.6 \pm 3.8, n=28$ & $117.2 \pm 5.0, n=15$ & 0.57 \\
\hline Diastolic BP, mmHg, mean $\pm \mathrm{SE}[60-90 \mathrm{~mm} \mathrm{Hg}]$ & $65.9 \pm 3.0, n=28$ & $68.6 \pm 4.3, n=15$ & 0.59 \\
\hline Mean BP, mmHg, median (IQR) [70-100 mm Hg] & $83.5(74.3-90.7), n=28$ & $88.0(67.7-93.3), \mathrm{n}=15$ & 0.57 \\
\hline Heart rate, beats $/ \mathrm{min}$, mean $\pm \mathrm{SE}[60-100$ beats $/ \mathrm{min}]$ & $104.0 \pm 4.7, n=28$ & $102.4 \pm 5.3, n=15$ & 0.83 \\
\hline Respiratory rate, breaths $/ \mathrm{min}$, mean $\pm \mathrm{SE}[12-20$ breaths $/ \mathrm{min}]$ & $18.8 \pm 1.4, n=28$ & $19.9 \pm 1.7, n=13$ & 0.64 \\
\hline Glasgow coma score, median (IQR) [15] & $15(15-15), n=28$ & $15(15-15), n=15$ & 0.56 \\
\hline \multicolumn{4}{|l|}{ Skin and limbs } \\
\hline Skin lesion & $85.2(23 / 27)$ & $73.3(11 / 15)$ & 0.43 \\
\hline Ulcer & $35.3(6 / 17)$ & $10(1 / 10)$ & 0.20 \\
\hline Exude & $27.8(5 / 18)$ & $18.2(2 / 11)$ & 0.68 \\
\hline Limb mottling & $26.7(4 / 15)$ & $60(6 / 10)$ & 0.12 \\
\hline Eschar & $17.7(3 / 17)$ & $18.2(2 / 11)$ & 1.00 \\
\hline Local pain & $100(19 / 19)$ & $85.7(12 / 14)$ & 0.17 \\
\hline Localized edema & $95.8(23 / 24)$ & $93.3(14 / 15)$ & 1.00 \\
\hline Local erythema & $87.0(20 / 23)$ & $92.3(12 / 13)$ & 1.00 \\
\hline Limb pain & $89.5(17 / 19)$ & $46.7(7 / 15)$ & 0.01 \\
\hline Limb edema & $84(21 / 25)$ & $46.7(7 / 15)$ & 0.03 \\
\hline \multicolumn{4}{|l|}{ Findings other than skin and limb } \\
\hline Fever & $60.9(14 / 23)$ & $66.7(8 / 12)$ & 1.00 \\
\hline Diaphoresis & $63.6(7 / 11)$ & $40(4 / 10)$ & 0.39 \\
\hline Lethargy & $64.3(9 / 14)$ & $41.7(5 / 12)$ & 0.25 \\
\hline Nausea & $29.4(5 / 17)$ & $30(3 / 10)$ & 1.00 \\
\hline Abdomen pain & $6.7(1 / 15)$ & $20(2 / 10)$ & 0.54 \\
\hline Confusion & $35.3(6 / 17)$ & $0(0 / 13)$ & 0.02 \\
\hline
\end{tabular}

*Values are \% patients (no. patients with the finding/no. patients for whom data were available) except as indicated. $\mathrm{n}$ values indicate no. patients for whom data were available. Bold indicates statistical difference between AIG-IV recipients and nonrecipients. AIG-IV, anthrax immune globulin intravenous; BP. blood pressure; IQR, interquartile range. 
Analysis of Anthrax Treatment

Table 4. Initial laboratory findings of AIG-IV recipients and nonrecipients, Scotland, UK, 2009-2010*

\begin{tabular}{|c|c|c|c|}
\hline Laboratory test [reference value] & Non-AIG-IV & AIG-IV & $p$ value \\
\hline \multicolumn{4}{|l|}{ Complete blood counts and differentials } \\
\hline Leukocytes, $\times 10^{9}$ cells/L, median (IQR) $\left[4-11 \times 10^{9} / \mathrm{L}\right]$ & $10.9(8.6-14.1), n=27$ & $18.9(9.5-23.2), \mathrm{n}=15$ & 0.02 \\
\hline Neutrophils, $\times 10^{9}$ cells $/ \mathrm{L}$, median (IQR) $\left[2-7 \times 10^{9} / \mathrm{L}\right]$ & $7.6(5.2-10.0), n=26$ & 15.4 (7.4-19.5), $\mathrm{n}=15$ & 0.008 \\
\hline Lymphocytes, $\times 10^{9}$ cells/L, median (IQR) [1-3 × 109/L] & $1.8(1.3-2.5), n=25$ & $2.0(1.3-2.7), n=15$ & 0.78 \\
\hline Hemoglobin, g/dL, mean \pm SE [12-18 g/dL] & $14.0 \pm 0.8, n=27$ & $14.8 \pm 1.5, n=15$ & 0.61 \\
\hline Hematocrit, $\%$, mean \pm SE $[35 \%-50 \%]$ & $41 \pm 2, n=23$ & $42 \pm 4, n=13$ & 0.86 \\
\hline Platelets, $\times 10^{9} / \mathrm{L}$, mean \pm SE $\left[150-450 \times 10^{9} / \mathrm{L}\right]$ & $214 \pm 19, n=24$ & $181 \pm 24, n=15$ & 0.29 \\
\hline \multicolumn{4}{|l|}{ Coagulation parameters and C-reactive protein } \\
\hline Prothrombin time(s), median (IQR) [11-13.5 s] & $11.0(10.0-14.0), n=15$ & $12.8(12.0-15.0), n=14$ & 0.94 \\
\hline Partial thromboplastin time(s), median (IQR) [25-35 s] & $26.7(24.0-36.0), n=10$ & $33.8(30.0-39.0), n=14$ & 0.63 \\
\hline International normalized ratio, median (IQR) [0.8-1.1] & $1.1(1.0-1.3), n=11$ & $1.1(1.0-1.3), n=11$ & 0.36 \\
\hline C-reactive protein, $\mathrm{nmol} / \mathrm{L}$, median (IQR) $[<95 \mathrm{nmol} / \mathrm{L}]$ & $21(8-49), n=25$ & $32(17-52), n=14$ & 0.24 \\
\hline \multicolumn{4}{|l|}{ Serum electrolytes and glucose } \\
\hline Sodium, mmol/L, median (IQR) [135-145 mmol/L] & $137(132-139), n=27$ & $135(131-136), n=15$ & 0.11 \\
\hline Chloride $\mathrm{mmol} / \mathrm{L}$, median (IQR) [96-108 mmol/L] & $100(96-101), n=13$ & $102(101-103), n=14$ & 0.76 \\
\hline Potassium, $\mathrm{mmol} / \mathrm{L}$, mean $\pm \mathrm{SE}[3.5-5.3 \mathrm{mmol} / \mathrm{L}]$ & $4.26 \pm 0.13, n=28$ & $4.35 \pm 0.22, n=13$ & 0.69 \\
\hline Calcium, mmol/L, median (IQR) $[2.25-2.5 \mathrm{mmol} / \mathrm{L}]$ & $2.3(2.0-2.3), \mathrm{n}=28$ & $2.1(2.0-2.3), \mathrm{n}=12$ & 0.97 \\
\hline $\mathrm{HCO}^{-}, \mathrm{mmol} / \mathrm{L}$, mean $\pm \mathrm{SE}[22-28 \mathrm{mmol} / \mathrm{L}]$ & $24.4 \pm 1.2, n=11$ & $20.7 \pm 0.9, n=11$ & 0.02 \\
\hline Glucose, $\mathrm{mmol} / \mathrm{L}$, median (IQR) [3.6-6.0 mmol/L] & $6.5(5.6-8.1), \mathrm{n}=16$ & $7.8(5.3-8.9), \mathrm{n}=10$ & 0.69 \\
\hline \multicolumn{4}{|l|}{ Renal and liver functions } \\
\hline Blood urea nitrogen, $\mathrm{mmol} / \mathrm{L}$, median (IQR) $[2.5-7.8 \mathrm{mmol} / \mathrm{L}]$ & $4.3(3.7-6.0), n=28$ & $8.6(7.1-13.9), n=15$ & 0.01 \\
\hline Creatinine, mmol/L, median (IQR) $[40-130 \mu \mathrm{mol} / \mathrm{L}]$ & $75.5(64.0-89.5), n=28$ & $102.0(84.0-189.0), n=15$ & 0.04 \\
\hline Bilirubin, $\mu \mathrm{mol} / \mathrm{L}$, median (IQR) [5-17 $\mu \mathrm{mol} / \mathrm{L}]$ & $8.0(5.0-11.0), n=25$ & $13.5(9.0-17.0), n=14$ & 0.02 \\
\hline Alanine aminotransferase, U/L, median (IQR) [<50 U/L] & $18.5(14-36.5), \mathrm{n}=16$ & $28.0(11.0-40.0), n=14$ & 0.69 \\
\hline Alkaline phosphatase, U/L, median (IQR) $[30-130 \mathrm{U} / \mathrm{L}]$ & $100(74-189), \mathrm{n}=15$ & $85(56-97), n=11$ & 0.04 \\
\hline Total protein, g/L, median (IQR) [60-80 g/L] & $67(65-75), n=12$ & $46(41-62), n=13$ & 0.001 \\
\hline Albumin, g/L, mean \pm SE $[35-55 \mathrm{~g} / \mathrm{L}]$ & $38.3 \pm 1.1, n=25$ & $27.6 \pm 2.6, n=14$ & $<0.0001$ \\
\hline
\end{tabular}

\section{Treatments of AIG-IV Recipients and Nonrecipients}

The median time to AIG-IV treatment in recipients was 1 day (IQR 1-3 days) (Figure 1; Table 6). No adverse events were documented during AIG-IV administration. A greater proportion of AIG-IV recipients than nonrecipients had surgery either on the day of (11 [73\%] of 15 vs. 5 [18\%] of $28 ; \mathrm{p}=0.0003)$ or at any time during $[14[93 \%]$ of 15 vs. $11[39 \%]$ of $28 ; p=0.0006]$ hospital admission (Figure 1; Table 6). AIG-IV recipients received more types of antimicrobial drugs than did nonrecipients (mean \pm SE $5.3 \pm$ 0.2 vs. $3.0 \pm 0.2 ; p<0.0001)$. Administration of mechanical ventilation or vasopressors did not differ between the groups ( $\mathrm{p} \geq 0.36$; data not shown).

\section{Outcomes}

Five (33\%) of 15 AIG-IV recipients and $6(21 \%)$ of 28 nonrecipients died, and these death rates did not differ significantly $(p=0.47)$ (Figure 1). However, in patients overall, risk for death at admission as reflected by the SOFA score was greater for AIG-IV recipients than for nonrecipients, although this finding did not reach statistical significance (median [IQR] 2 [0-7] vs. 0.5 [0-2.5]; $\mathrm{p}=0.14$ ). However, SOFA scores were not distributed equally between recipients and nonrecipients (Figure 2). Of the 30 patients with a SOFA score of $0-5$ (indicating a low risk for death), only $8(27 \%)$ received AIG-IV ( $p=0.01$, against the null hypothesis that $50 \%$ of these patients received AIG-IV).
On the other hand, of the 13 patients with a SOFA score of 6-11 (indicating a higher risk for death), 7 (54\%) received AIG-IV ( $\mathrm{p}=0.78$, against the null hypothesis that $50 \%$ of these patients received AIG-IV). Death rates did not differ between AIG-IV recipients and nonrecipients either for patients with SOFA scores of 0-5 (1 [13\%] nonsurvivor of 8 recipients vs. 1 [5\%] of 22 nonrecipients; $p=0.47$ ) or for patients with SOFA scores of 6-11 (4 [57\%] of 7 recipients vs. $5(83 \%)$ of 6 nonrecipients, $p=0.56]$. For patients with SOFA scores of $6-11$, the median score was higher in nonrecipients than recipients $(8.5[8-11]$ vs. $7[6-8] ; p=0.03)$.

For survivors, duration of ICU and hospital stays were longer for recipients than for nonrecipients (median [IQR] for ICU stay, 4.5 [0.9-19.0] vs. 0 [0-0]; $p=0.0008$; for hospital stay, 38.0 [31.0-42.0] vs. $9.5[2.0-17.0] ; \mathrm{p}=0.001$ ) (Figure 1; Table 6). For nonsurvivors, the time to death was longer for recipients than for nonrecipients in a pattern approaching significance $(4.0$ [3.0-5.0] vs. 1.3 [0.6-2.0]; $\mathrm{p}=0.07)$ (Figure 1; Table 6). Of the 6 nonsurvivors not receiving AIG-IV, 3 died within $24 \mathrm{~h}$ and 2 within $48 \mathrm{~h}$ after admission, times possibly too short for AIG-IV acquisition and treatment. Furthermore, nonsurvivors receiving AIG-IV had significantly higher GCS (better neurologic function) than nonrecipients (15 [15-15] vs. 9 [6-14]; p $=0.04)$. Consistent with this finding, all 4 head computed tomograms reported from patients in the outbreak were in nonrecipient nonsurvivors, and all showed evidence of 
Table 5. Microbiology data and the time to confirmatory anthrax diagnosis for recipients and nonrecipients of AIG-IV, Scotland, UK, 2009-2010*

\begin{tabular}{|c|c|c|c|}
\hline Laboratory test & AIG-IV nonrecipient & AIG-IV recipient & $p$ value \\
\hline Blood culture & $32(8 / 25)$ & $71.4(10 / 14)$ & 0.02 \\
\hline Wound culture & $46.2(6 / 13)$ & $33.3(3 / 9)$ & 0.67 \\
\hline Tissue culture & $54.6(6 / 11)$ & $70(7 / 10)$ & 0.66 \\
\hline Blood PCR & $29.4(5 / 17)$ & $80(8 / 10)$ & 0.02 \\
\hline Blood protective antigen antibody & $81.3(13 / 16)$ & $66.7(4 / 6)$ & 0.59 \\
\hline Blood lethal factor antibody & $62.5(10 / 16)$ & $57.1(4 / 7)$ & 1.00 \\
\hline Days to diagnosis, median (IQR) & $3.5(2.0-30.5), n=28$ & $2.0(1.0-3.0), n=13$ & 0.006 \\
\hline
\end{tabular}

subarachnoid hemorrhage ( 3 patients) or high attenuation material caused by subarachnoid hemorrhage or purulence (1 patient). Two of these nonrecipients died within $15 \mathrm{~h}$ after admission and 2 by $48 \mathrm{~h}$. In addition, although all nonsurvivors receiving AIG-IV had at least 1 surgery, no nonsurvivor not receiving AIG-IV had surgery (Figure 1).

\section{Four Patients from the Outbreak for Whom Data Were Unavailable}

None of the 4 patients for whom data were unavailable received AIG-IV. Of these, 2 survived and 2 did not (25). Therefore, across all 47 patients in Scotland, the proportion of patients dying did not differ significantly between AIGIV recipients and nonrecipients $(5[33 \%]$ of 15 vs. 8 [25\%] of $32 ; \mathrm{p}=0.73$ ).

\section{LF Levels in AIG-IV Recipients}

LF levels were available for 5 nonsurvivors and 7 survivors receiving AIG-IV and from no nonrecipients. These levels were examined over the period they were available for both nonsurvivors and survivors $(10 \mathrm{~h}$ before and up to $50 \mathrm{~h}$ after AIG-IV administration). Before AIG-IV treatment, LF levels trended to be higher but did not differ significantly between nonsurvivors and survivors $(\mathrm{p}=0.42)$ (Figure 3 ). Two survivors had LF levels $<0.1 \mathrm{ng} / \mathrm{mL}$, noticeably lower than levels of other patients. After AIG-IV treatment, levels trended slightly lower and with a common slope approaching significance $(\mathrm{p}=0.08)$.

\section{Discussion}

The experience with AIG-IV during the 2009-2010 anthrax outbreak in injection drug users in Scotland is, to our knowledge, the largest single experience with this agent. Despite AIG-IV efficacy in animal models $(11,12)$, death rates did not differ significantly between 15 patients who did and the 28 who did not receive therapy. However, several criteria indicated that AIG-IV recipients were sicker than nonrecipients, and this difference confounds an assessment of the efficacy of AIG-IV.

Although SOFA scores seemed to suggest that AIGIV recipients were at higher risk than nonrecipients for death, this trend did not reach significance $(p=0.14)$. However several laboratory findings differed significantly between the 2 groups and were consistent with more severe disease in AIG-IV recipients: lower temperature, serum bicarbonate, total protein, and albumin and higher leukocytes, neutrophils, blood urea nitrogen, creatinine, and bilirubin. Patients with a low risk for death (SOFA score $\leq 5$ ) were less likely to receive AIG-IV (8 of 30; $p=0.01)$. In contrast, the proportions of recipients and

\begin{tabular}{|c|c|c|c|}
\hline Treatment characteristic & AIG-IV nonrecipient & AIG-IV recipient & $p$ value \\
\hline \multicolumn{4}{|l|}{ Treatments after hospital admission } \\
\hline Days to AIG-IV receipt, median (IQR) & NA & $1(1-3), n=15$ & NA \\
\hline ICU care & $35.7(10 / 28)$ & $86.7(13 / 15)$ & 0.001 \\
\hline Receipt of antimicrobial drugs & $100(28 / 28)$ & $100(15 / 15)$ & 1.00 \\
\hline No. antimicrobial drugs/patient during hospital stay, mean \pm SE $\ddagger$ & $3.0 \pm 0.2, n=28$ & $5.3 \pm 0.2, n=15$ & $<0.0001$ \\
\hline Surgery on day of admission & $17.9(5 / 28)$ & $73.3(11 / 15)$ & 0.0003 \\
\hline Surgery during hospital stay & $39.3(11 / 28)$ & $93.3(14 / 15)$ & 0.0006 \\
\hline Days to surgery, median (IQR) & $1(0-2), n=11$ & $0(0-0.33), n=14$ & 0.24 \\
\hline Vasopressors & $13.3(2 / 15)$ & $33.3(4 / 12)$ & 0.36 \\
\hline Mechanical ventilation & $33.3(5 / 15)$ & $50(7 / 14)$ & 0.36 \\
\hline \multicolumn{4}{|l|}{ Duration of ICU and hospital stay, median (IQR) } \\
\hline Survivors' ICU stay, d & $0, n=22$ & $4.5(0.9-19.0), \mathrm{n}=10$ & 0.0008 \\
\hline Nonsurvivors' time to death, $d$ & $1.3(0.6-2.0), n=6$ & $4.0(3.0-5.0), n=5$ & 0.07 \\
\hline Survivors' hospital stay, $\mathrm{d}$ & $9.5(2.0-17), \mathrm{n}=22$ & $38(31-42), n=10$ & 0.001 \\
\hline
\end{tabular}

*Values are \% patients (no. patients with the finding/no. patients for whom data were available) except as indicated. $\mathrm{n}$ values indicate no. patients for whom data were available. Bold indicates significant differences between AIG-IV recipients and nonrecipients. AIG-IV, anthrax immune globulin intravenous; ICU, intensive care unit; IQR, interquartile range; NA, not applicable. 

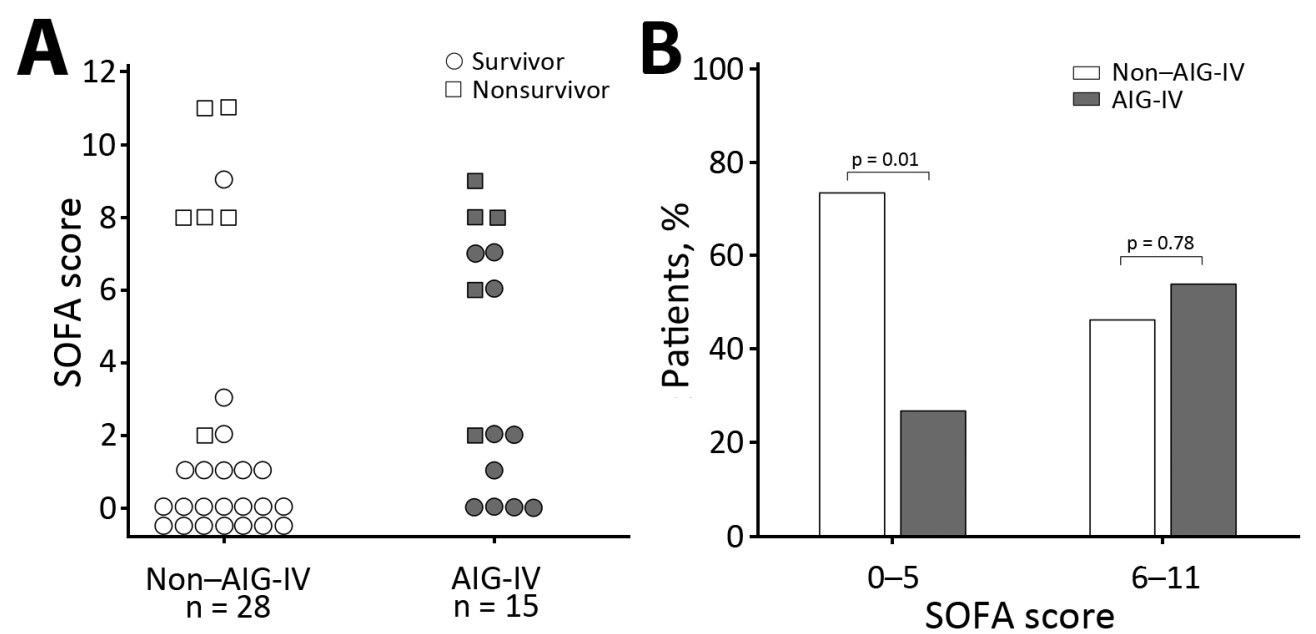

Figure 2. SOFA scores of injection drug users who did and did not receive AIG-IV, Scotland, UK, 2009-2010. A) Individual SOFA scores for patients who did or did not receive AIG-IV and did or did not survive. B) Proportion of patients who did or did not receive AIG-IV for those who had admission SOFA scores of $0-5$ and a low risk for death and for those with SOFA scores of 6-11 and a higher risk for death. AIG-IV, anthrax immune globulin intravenous; SOFA, sequential organ failure.

nonrecipients with a higher risk for death (SOFA scores $\geq 6$ ) did not differ. The number of patients with higher SOFA scores was too small to assess AIG-IV effects in this subgroup. Consistent with the possibility that AIG-IV recipients were sicker than nonrecipients, among survivors, ICU and hospital stay were significantly longer for recipients, suggesting longer recovery from more severe disease. More AIG-IV recipients than nonrecipients had surgery to manage their disease, and a greater proportion of AIG-IV recipients had blood cultures positive for $B$. anthracis, suggesting a higher bacterial load.

For at least 3 reasons, AIG-IV treatment might have been directed to more severely ill patients. First, the sensitivity of various diagnostic laboratory criteria for documenting anthrax can vary on the basis of the severity of infection. Positive blood cultures, suggestive of significant bacterial load, often were available early during the patient's course (i.e., within $\leq 1$ day), resulting in timely consideration of AIG-IV. In contrast, confirmation based solely on paired serum samples, reflecting less severe infection, required far longer for results to be available (often weeks), thus mitigating against AIG-IV use. Second, criteria for AIG-IV stipulated that patients have evidence of systemic and therefore more severe illness. Third, outbreak treatment teams reported in personal communications to authors of this article (L.N. and M.B.) that AIG-IV was considered a limited resource and that treatment was directed to patients with evidence of more severe infection but with a likelihood of survival.

For at least 2 possible reasons, some patients with high SOFA scores did not receive AIG-IV. First, disease might have progressed too quickly in some nonsurvivors for AIG-IV to be made available; 3 nonrecipients died within $24 \mathrm{~h}$ after seeking care and 2 within $48 \mathrm{~h}$. Second, among nonsurvivors, nonrecipients had significantly poorer neurologic status at admission, as assessed by GCS scores, than did AIG-IV recipients, and none underwent surgery, suggesting that care might have been limited in these patients. In fact, 4 of these patients had evidence of subarachnoid hemorrhage soon after seeking care. In personal communications, caregivers reported withholding AIG-IV in patients with severe neurologic deficits.

Thus, on the basis of experience during this outbreak in injection drug users, whether AIG-IV provides benefit for anthrax-related soft tissue infection is unclear. This form of infection has only recently been identified and has received little preclinical study. Debridement was effective in a mouse model of subcutaneous anthrax, but that study did not investigate the efficacy of antitoxin therapies (29). The preclinical models on which FDA based its approval of AIG-IV all used aerosolized bacterial challenge to simulate inhalational anthrax $(11,12)$. In these studies, AIG-IV added to the protective effects of antimicrobial drugs when both treatments were administered after the onset of lethality, in trends that approached significance (11). The prior clinical experience with AIG-IV also has been restricted to inhalational disease (3 cases) or gastrointestinal disease (1 case) contracted by inhalation or ingestion of spores (1316). Although 3 of these 4 patients survived, an overall survival rate higher than previously reported with these forms of disease, to what extent this might have been related to AIG-IV treatment or other factors is unknown. Studies examining the effects of AIG-IV or other antitoxin agents when combined with antimicrobial drugs and debridement in animal models are necessary to better define the optimal therapeutic approach for this newly identified form of anthrax. Prompt and aggressive antimicrobial therapy and surgical debridement if necrotic tissue requires it, remain the mainstays of management for soft tissue infection when anthrax is suspected. However, on the basis of animal efficacy studies with other forms of anthrax, as well as human 


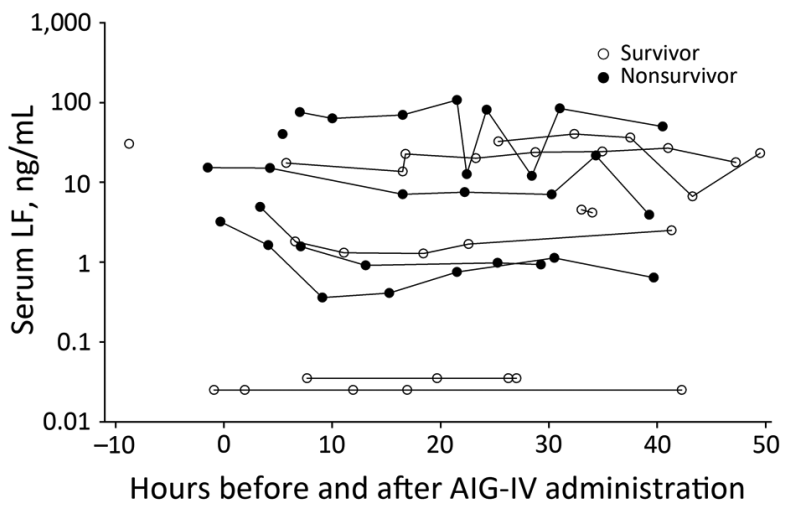

Figure 3. Individual LF levels (nanograms per milliliter) in 12 anthrax patients receiving AIG-IV from $10 \mathrm{~h}$ before until $50 \mathrm{~h}$ after treatment administration, Scotland, UK, 2009-2010. AIG-IV, anthrax immune hlobulin intravenous; LF, lethal factor.

safety studies, AIG-IV or other approved antitoxin agents still might be considered as adjunctive therapy when clinical suspicion is high for systemic anthrax.

LF levels trended higher in nonsurvivors than survivors before AIG-IV administration, but this difference was not significant. Although there was a small but close to significant reduction in LF levels after AIG-IV administration, without data from nonrecipients, determining whether this decline reflects the effect of antibody treatment or the course of the infection itself is not possible. LF levels could have been influenced by previous antimicrobial use. Although current LF detection is based on serum and plasma levels, the relationship between these and tissue levels is currently under investigation. Tissue levels ultimately might be more instructive than serum and plasma levels for disease treatment.

No adverse events related to AIG-IV administration were reported to CDC during this B. anthracis outbreak. The number of recipients was relatively small, however, and given these patients' severity of disease, identifying adverse effects of treatment without an equivalent control group would be difficult.

This study has limitations. First, data were obtained retrospectively and not completely for all patients. However, parameters were analyzed and presented only if available from $>50 \%$ of patients. Furthermore, the SOFA score on which stratification of AIG-IV treatment and survival data was based, and which is a well-regarded gauge of disease severity and lethality risk (27), was available for all 43 patients analyzed. Second, data were not available regarding decisions about whether individual patients should or should not receive AIG-IV treatment. Third, the overall number of patients available for analysis was small. However, our analysis addressed the single largest experience with an antitoxin agent for treating anthrax since the introduction of antimicrobial drugs during the 1940s and the routine use of modern ICU support in the early1960s (30).

In conclusion, guidelines now recommend treatment with agents inhibiting the effects of lethal and edema toxins for patients with a high likelihood of having systemic anthrax infection. AIG-IV is one of the few antitoxin agents that has received FDA approval and been included in the Strategic National Stockpile. Documenting the clinical experience with anthrax antitoxin agents is critical for further defining this therapeutic approach. Whether AIG-IV treatment is effective for systemic anthrax soft tissue infection related to drug injection cannot be answered with currently available data.

\section{Acknowledgments}

We thank Yon Yu and Tina Bhavsar for their contributions and clarifications about AIG-IV E-IND data collected under the CDC-sponsored E-IND.

C.X. and P.Q.E. have received study reagents from Human Genome Sciences for other investigations.

The work was supported by the National Institutes of Health Intramural Research Program and the Clinical Center and by CDC.

Dr. Cui is a staff scientist in the Critical Care Medicine Department, Clinical Center, National Institutes of Health. His research interests include understanding the mechanisms and improving the treatment of anthrax infection and sepsis.

\section{References}

1. Possession, Use, and Transfer of Select Agents and Toxins, 7 CFR Part 331 [cited 2016 Nov 10]. http://www.ecfr.gov/cgi-bin/retrieve ECFR?gp=1\&SID=b9126e9fba23e3e7933354a1d2630d72\&ty=HT ML\&h=L\&n=7y5.1.1.1.9\&r=PART

2. Possession, Use, and Transfer of Select Agents and Toxins, 9 CFR Part 121 [cited 2016 Nov 10]. http://www.ecfr.gov/cgi-bin/retrieve ECFR?gp=1\&SID=b9126e9fba23e3e7933354a1d2630d72\&ty=HT $\mathrm{ML} \& \mathrm{~h}=\mathrm{L} \& \mathrm{n}=9 \mathrm{y} 1.0 .1 \cdot 5.58 \& \mathrm{r}=\mathrm{PART}$

3. Select Agents and Toxins, 42 CFR Part 73 [cited 2016 Nov 10]. http://www.ecfr.gov/cgi-bin/retrieveECFR?gp=\&SID=8a4be60456 973b5ec6bef5dfeaffd49a\&r=PART \&n=42y1.0.1.6.61

4. Adalja AA, Toner E, Inglesby TV. Clinical management of potential bioterrorism-related conditions. N Engl J Med. 2015;372:954-62. http://dx.doi.org/10.1056/NEJMra1409755

5. Jernigan JA, Stephens DS, Ashford DA, Omenaca C, Topiel MS, Galbraith M, et al.; Anthrax Bioterrorism Investigation Team. Bioterrorism-related inhalational anthrax: the first 10 cases reported in the United States. Emerg Infect Dis. 2001;7:933-44. http://dx.doi.org/10.3201/eid0706.010604

6. Moayeri M, Leppla SH. Cellular and systemic effects of anthrax lethal toxin and edema toxin. Mol Aspects Med. 2009;30:439-55. http://dx.doi.org/10.1016/j.mam.2009.07.003

7. Popov SG, Villasmil R, Bernardi J, Grene E, Cardwell J, Popova T, et al. Effect of Bacillus anthracis lethal toxin on human peripheral blood mononuclear cells. FEBS Lett. 2002;527:211-5. http://dx.doi.org/10.1016/S0014-5793(02)03228-3

8. Sherer K, Li Y, Cui X, Eichacker PQ. Lethal and edema toxins in the pathogenesis of Bacillus anthracis septic shock: implications for therapy. Am J Respir Crit Care Med. 2007;175:211-21. http://dx.doi.org/10.1164/rccm.200608-1239CP 
9. Hendricks KA, Wright ME, Shadomy SV, Bradley JS, Morrow MG, Pavia AT, et al.; Workgroup on Anthrax Clinical Guidelines. Centers for disease control and prevention expert panel meetings on prevention and treatment of anthrax in adults. Emerg Infect Dis. 2014;20:20. http://dx.doi.org/10.3201/eid2002.130687

10. Wright JG, Quinn CP, Shadomy S, Messonnier N; Centers for Disease Control and Prevention (CDC). Use of anthrax vaccine in the United States: recommendations of the Advisory Committee on Immunization Practices (ACIP), 2009. MMWR Recomm Rep. 2010;59(RR-6):1-30.

11. Kammanadiminti S, Patnaikuni RK, Comer J, Meister G, Sinclair C, Kodihalli S. Combination therapy with antibiotics and anthrax immune globulin intravenous (AIGIV) is potentially more effective than antibiotics alone in rabbit model of inhalational anthrax. PLoS One. 2014;9:e106393. http://dx.doi.org/10.1371/ journal.pone. 0106393

12. Mytle N, Hopkins RJ, Malkevich NV, Basu S, Meister GT, Sanford DC, et al. Evaluation of intravenous anthrax immune globulin for treatment of inhalation anthrax. Antimicrob Agents Chemother. 2013;57:5684-92. http://dx.doi.org/10.1128/AAC.00458-13

13. Anaraki S, Addiman S, Nixon G, Krahé D, Ghosh R, Brooks T, et al. Investigations and control measures following a case of inhalation anthrax in East London in a drum maker and drummer, October 2008. Euro Surveill. 2008;13:19076.

14. Klempner MS, Talbot EA, Lee SI, Zaki S, Ferraro MJ. Case records of the Massachusetts General Hospital. Case 25-2010. A 24-year-old woman with abdominal pain and shock. N Engl J Med. 2010;363:766-77. http://dx.doi.org/10.1056/NEJMcpc1003887

15. Sprenkle MD, Griffith J, Marinelli W, Boyer AE, Quinn CP, Pesik NT, et al. Lethal factor and anti-protective antigen IgG levels associated with inhalation anthrax, Minnesota, USA. Emerg Infect Dis. 2014;20:310-4. http://dx.doi.org/10.3201/eid2002.130245

16. Walsh JJ, Pesik N, Quinn CP, Urdaneta V, Dykewicz CA, Boyer AE, et al. A case of naturally acquired inhalation anthrax: clinical care and analyses of anti-protective antigen immunoglobulin G and lethal factor. Clin Infect Dis. 2007;44:96871. http://dx.doi.org/10.1086/512372

17. Beaumont G. Anthrax in a Scottish intravenous drug user. J Forensic Leg Med. 2010;17:443-5. http://dx.doi.org/10.1016/j. jflm.2010.09.008

18. Booth M, Donaldson L, Cui X, Sun J, Cole S, Dailsey S, et al. Confirmed Bacillus anthracis infection among persons who inject drugs, Scotland, 2009-2010. Emerg Infect Dis. 2014;20:1452-63. http://dx.doi.org/10.3201/eid2009.131481

19. Booth MG, Hood J, Brooks TJ, Hart A; Health Protection Scotland Anthrax Clinical Network. Anthrax infection in drug users. Lancet. 2010;375:1345-6. http://dx.doi.org/10.1016/S01406736(10)60573-9

20. Jallali N, Hettiaratchy S, Gordon AC, Jain A. The surgical management of injectional anthrax. J Plast Reconstr Aesthet Surg. 2011;64:276-7.
21. Johns N, Cooper D, Terrace J. An unusual case of peritonitis in an intravenous drug user. Gastroenterology. 2011;141:435-6, 780-1. http://dx.doi.org/10.1053/j.gastro.2011.02.076

22. Knox D, Murray G, Millar M, Hamilton D, Connor M, Ferdinand RD, et al. Subcutaneous anthrax in three intravenous drug users: a new clinical diagnosis. J Bone Joint Surg Br. 2011;93:414-7. http://dx.doi.org/10.1302/0301-620X.93B3.25976

23. Parcell BJ, Wilmshurst AD, France AJ, Motta L, Brooks T, Olver WJ. Injection anthrax causing compartment syndrome and necrotising fasciitis. J Clin Pathol. 2011;64:95-6. http://dx.doi.org/ 10.1136/jcp.2010.082586

24. Price EP, Seymour ML, Sarovich DS, Latham J, Wolken SR, Mason J, et al. Molecular epidemiologic investigation of an anthrax outbreak among heroin users, Europe. Emerg Infect Dis. 2012;18:1307-13.

25. Scotland HP. An outbreak of anthrax among drug users in Scotland, December 2009 to December 2010, A report on behalf of the National Anthrax Outbreak Control Team. December 2011 [cited 2016 Apr 4]. http://wwwdocumentshpsscotnhsuk/giz/anthraxoutbreak/anthrax-outbreak-report-2011-12pdf

26. Gallegos-Candela M, Boyer AE, Quinn CP, Woolfitt AR, Barr JR. Validation of rapid, sensitive, quantitative MALDI-TOF MS assays for anthrax lethal factor and lethal toxin. Bacillus-ACT 2009: The International Bacillus anthracis, B cereus, and B thuringiensis conference; 2009 Aug 30-Sep 3; Santa Fe (NM).

27. Vincent JL, Moreno R, Takala J, Willatts S, De Mendonça A, Bruining $\mathrm{H}$, et al. The SOFA (sepsis-related organ failure assessment) score to describe organ dysfunction/failure. On behalf of the Working Group on Sepsis-Related Problems of the European Society of Intensive Care Medicine. Intensive Care Med. 1996;22:707-10. http://dx.doi.org/10.1007/ BF01709751

28. Health Protection Scotland. Interim clinical guidance for the management of suspected anthrax in drug users [cited $2016 \mathrm{Apr}$ 4]. http://wwwdocumentshpsscotnhsuk/giz/anthrax-outbreak/ clinical-guidance-for-use-of-anthrax-immune-globulin-v121-2010-03-19pdf

29. Weiner ZP, Boyer AE, Gallegos-Candela M, Cardani AN, Barr JR, Glomski IJ. Debridement increases survival in a mouse model of subcutaneous anthrax. PLoS One. 2012;7:e30201. http://dx.doi.org/10.1371/journal.pone.0030201

30. Kelly FE, Fong K, Hirsch N, Nolan JP. Intensive care medicine is 60 years old: the history and future of the intensive care unit. Clin Med (Lond). 2014;14:376-9. http://dx.doi.org/10.7861/ clinmedicine.14-4-376

Address for correspondence: Peter Q. Eichacker, Critical Care Medicine Department, National Institutes of Health, Bldg 10, Rm 2C145, Bethesda, MD 20892,USA; email: peichacker@mail.nih.gov 